\title{
José Ma. Portillo Valdés, Fuero indio. Tlaxcala y la identidad territorial entre la monarquía imperial y la república nacional, 1787-1824, México, El Colegio de México/Instituto Mora, 2015, 259 pp.
}

Fuero Indio explica cómo, durante los convulsos años de finales del siglo XVIII y principios del XIX, la pequeña provincia indígena de Tlaxcala defendió su autonomía territorial para convertirse en un estado federado de la nación mexicana. Esta obra, comparada con varios estudios sobre el territorio y el surgimiento del Estado-nación, utiliza un enfoque diferente, basado en el análisis jurídico-histórico del territorio, y plantea una hipótesis sugerente: la identidad foral definió el estatus territorial de Tlaxcala como provincia de la monarquía española y después como estado federal de la nación mexicana. El término identidad foral, pilar argumentativo del libro, se refiere a la identidad territorial desarrollada por las provincias hispanas a partir de tres elementos: el reconocimiento de un derecho (consuetudinario y escrito), la presencia de un cuerpo político gobernante (autoridades reconocidas como legítimas) y una jurisdicción territorial (pp. 18-19). Desde esta perspectiva, el autor estudia el rompecabezas de los conflictos políticos y los procesos judiciales concernientes a los derechos y la autonomía de Tlaxcala durante los años 1780-1824.

El primer capítulo está dedicado a explicar cómo América fue incorporada por la Corona castellana -en términos jurídico-políticos- como un espacio de derecho real y municipal, situación que promovió el desarrollo de provincias autónomas con arraigadas identidades locales. José María Portillo explica que el gobierno de los Habsburgo (dinastía gobernante durante los siglos XVI-XVII) en América se apoyó fundamentalmente en los municipios, cuerpos políticos autónomos con territorio y jurisdicción, unidos a la monarquía por la fe católica y la figura del rey. De esta forma, la Corona impidió la señoralización del territorio americano pues el gobierno recayó en las autoridades regias que abarcaban distintas jurisdicciones. Al considerar este proceso, Portillo explica que la Corona castellana incorporó y gobernó el antiguo señorío y territorio de Tlaxcala mediante un pacto de vasallaje, el cual confirió privilegios a la provincia india por su participación en la conquista. Por esta razón, y al considerar el espacio atlántico que abarcaba la monarquía española, Portillo compara a Tlaxcala con Vizcaya -ubicada al norte de España-, pues ambas fueron provincias forales que 
utilizaron estrategias y argumentos similares para defender su autonomía cuando la dinastía de los Borbones asumió el poder e impuso una nueva "moral imperial"

En el segundo capítulo, Portillo explica este cambio en la "moral imperial” con el análisis de la Real Ordenanza de Intendentes (1786), documento que ejemplifica cómo los Borbones intentaron "imperializar" sus territorios al dotarles de una nueva organización que imponía el interés administrativo y fiscal sobre los privilegios locales. Sin embargo, a lo largo del capítulo el autor demuestra que la "imperialización” del territorio tlaxcalteca no ocurrió debido a la efectiva reacción del cabildo indio y del gobernador español. Éstos, al recurrir a la memoria histórica de Tlaxcala, presentaron ante la Corona un discurso republicano, de méritos y de colaboración, para legitimar los privilegios de la provincia india. De esta manera, las élites tlaxcaltecas defendieron su autonomía y evitaron ser sometidas al control político y militar de la intendencia de Puebla. Así, Portillo demuestra que la lógica de gestión administrativa e “imperialización” promovidas por los Borbones no pudieron terminar con las identidades forales, las cuales se hicieron efectivas tanto en las instituciones y las jurisdicciones de las provincias hispanas.

No obstante, los éxitos de Tlaxcala en la defensa de su fuero no impidieron que al interior de la provincia surgieran críticas en contra del gobierno tradicional de los caciques, al no poder éstos solucionar los problemas sociales y económicos que la región enfrentó a principios del siglo XIX. Así, el tercer capítulo explica cómo los caciques de la ciudad india de Tlaxcala asumieron como suya la foralidad para excluir del poder a los cientos de pueblos de indios que conformaban la provincia; pese a que éstas mismas comunidades se valieron del mismo instrumento jurídico para luchar por una distribución del poder político. En medio de esta lucha interna, Tlaxcala recibió la crisis de la monarquía en 1808. En aquel momento, la provincia india renovó su pacto de fidelidad y alianza con la Corona española, al conseguir el derecho a votar en la elección de diputado de la Nueva España para la Junta Central, la cual había asumido la soberanía del depuesto y cautivo rey Fernando VII. El cuarto capítulo explica este proceso y muestra cómo, ante la crisis monárquica, Tlaxcala y las demás provincias novohispanas utilizaron un lenguaje corporativo y foral pues se asumieron como parte de un reino que debía ser representado. 
Portillo explica que aquello obedecía a la lógica de antiguo régimen en la que los territorios eran entendidos como cuerpos políticos con derechos de representación. El autor considera que esta situación prevaleció con la llegada del constitucionalismo gaditano. Portillo considera que, a diferencia del constitucionalismo francés que concibió a los territorios como entidades administrativas al liquidar los antiguos fueros provinciales, el constitucionalismo gaditano integró y transformó las identidades forales, no las desechó. Para llegar a esta conclusión, en el quinto capítulo Portillo analiza cómo Tlaxcala, ante el paradigma constitucional, reelaboró su identidad foral para integrarse al nuevo sujeto político que reemplazó al monarca como ente soberano: la nación española y, posteriormente, la nación mexicana.

Los argumentos de José Miguel Guridi y Alcocer, elegido como diputado provincial de Tlaxcala ante las Cortes de Cádiz, nos muestran cómo el discurso foral fue adaptado al nuevo contexto liberal y constitucional para defender la igualdad política de las provincias americanas. A pesar de los intentos de Alcocer y la mayoría de los diputados americanos por construir una nación española de extensión atlántica, finalmente las Cortes de Cádiz refrendaron el imperialismo de la España peninsular sobre la España americana. Entonces, ocurrieron las independencias. No obstante, el autor considera que la constitución de Cádiz, aunque no consolidó una nación atlántica, sí transformó profundamente las provincias forales con el establecimiento de elecciones para ayuntamientos. Con el sistema electoral gaditano, los tradicionales caciques perdieron sus posiciones privilegiadas de poder ante el ingreso de nuevos personajes no indios, como criollos y mestizos. A su vez, los cientos de pueblos que formaban la provincia tlaxcalteca aprovecharon la coyuntura constitucionalista para formar sus propios ayuntamientos y desprenderse así de la sujeción de la ciudad de Tlaxcala.

Finalmente, en el último capítulo, el autor estudia el proceso de transformación y adaptación de la identidad foral tlaxcalteca ante la formación de la primera república federal mexicana, ya durante la época independiente. El sexto capítulo explica que el primer federalismo mexicano, al reconocer la soberanía en la nación y no en los estados, permitió a los antiguos territorios novohispanos incorporarse a la nación mexicana como entes políticos con capacidad de gobierno y gestión del territorio, cual si fueran provincias forales en la época de los Habsburgo. El autor afirma así: "Ser o no ser estado resultó, entonces, determinante para poder participar en ese reparto federal del gobierno y la administratio" (p. 243). Por esta 
razón, Tlaxcala buscó y luchó en la tribuna política su reconocimiento como estado de la federación. Si la provincia logró su cometido, primero al conseguir el estatus de "territorio de la federación” (1824) y finalmente convertirse en un estado federal (1857), fue porque pudo reelaborar su identidad foral para preservar su territorialidad e identidad política. Para ello, el viejo discurso foral transmutó a uno liberal: Tlaxcala ahora tenía un pasado republicano y democrático, dejó de ser la provincia aliada de la Corona española para convertirse, bajo el mito patriótico de Xicoténcatl el Joven, en la valiente opositora de los conquistadores españoles.

Así, José Ma. Portillo cumple su objetivo inicial y logra explicar cómo la identidad foral permitió a las provincias hispanas -como Tlaxcala- asimilar el constitucionalismo y, posteriormente, insertarse en las naciones emancipadas de la monarquía española. Los aportes historiográficos del libro son varios, aunque destacan dos en particular. Por una parte, Fuero indio ofrece un análisis sobre el territorio con perspectiva atlántica y de larga duración, el cual permite una comprensión más amplia sobre el surgimiento del Estado nacional mexicano a principios del siglo XIX. Por otra parte, la obra de Portillo complementa los últimos aportes de la etnohistoria mexicana desde una perspectiva jurídico-política. Al respecto, la obra abre una vía para entender cómo las Repúblicas de Indios y los caciques interpretaron el nuevo paradigma constitucional gaditano y el primer federalismo, bajo la lógica de los fueros y los antiguos pactos de vasallaje que otrora habían sido prestados ante la Corona castellana y ahora debían ser renovados ante la nación mexicana.

Abisai Pérez Zamarripa Escuela Militar de Sargentos Secretaría de la Defensa Nacional, México abisai.perez@alumnos.cide.edu 